РАЗОВ Павел Викторович - доктор социологических наук, профессор; заместитель руководителя департамента социологии по учебно-методической работе Финансового университета при Правительстве РФ (125993, Россия, г. Москва, Ленинградский np-кm, 49; PVRazov@fa.ru)

БАШКАТОВ Никита Евгеньевич - бакалавр факультета социальных наук и массовых коммуникаций Финансового университета при Правительстве РФ (125993, Россия, г. Москва, Ленинградский np-кm, 49; bas.nick00@icloud.com)

\title{
ФОРМИРОВАНИЕ ПОТРЕБИТЕЛЬСКОГО ПОВЕДЕНИЯ СТУДЕНТОВ РОССИЙСКИХ ВУЗОВ ПОД ВОЗДЕЙСТВИЕМ КРЕДИТНОГО ПРОДУКТА
}

\begin{abstract}
Аннотация. В статье рассматриваются субъективные и объективные факторы, которые формируют определенное потребительское поведение студентов российских вузов под воздействием кредитного продукта. Авторы изучают степень влияния различных социальных групп на индивида в условиях социализации в студенческой среде, выявляют уровень взаимодействия индивида с социальными сетями, специальные условия для студента в кредитных организациях, а также рассматривают влияние финансового положения и социального статуса в обществе на формирование потребительского поведения у студента.
\end{abstract}

Ключевые слова: социальный риск, потребительский кредит, кредитование в студенческой среде, потребительское поведение, кредитный продукт, общество риска

$\mathrm{H}$ а социальное поведение современного студента в обществе влияет множество факторов. В процессе социализации студент приобретает различные потребности: экономические, духовные, социальные, политические, которые оказывают влияние на всю последующую жизнь. Индивид постоянно находится в социальном движении: новые социальные группы, течения в моде, тренды, социальные сети - все это влияет на его ценностные установки и восприятие мира. Студент находится на этапе перехода во взрослую жизнь, где люди имеют больше материальных благ, находясь в окружении люксовых автомобилей, различных брендов одежды, различных успешных образов в социальных сетях. У индивида начинает развиваться потребность обладания этими материальными благами, а влияние рекламы и доступность потребительского кредита среди студентов только обостряют данную ситуацию. Оказываясь в данной среде, индивид берет потребительский кредит, не осознавая все его недостатки.

С одной стороны, кредит может помочь студентам в краткий срок получить определенную сумму денег для покупки товара, инвестирования в бизнес, игры на бирже или для проведения своего досуга. С другой стороны, кредит может отрицательно повлиять на студента в случае его невыплаты. Так, имеется риск дополнительных финансовых потерь в случае невыплаты долга в срок, что влечет за собой рост конфликтов в семье, изменение отношений с друзьями, риск девиантного поведения в университете, а также в обществе.

В современной России, несмотря на меньшее число людей, которые берут кредиты, данный продукт все же пользуется спросом. На сегодняшний день больше половины россиян имеют непогашенные кредиты (51\%). Сегодня кредиты в большей степени имеют люди в возрасте от 25 до 34 лет (72\%). Реже 
обращается к такой стратегии молодежь в возрасте от 18 до 24 лет (37\%) ${ }^{1}$. Как подсчитали аналитики Всероссийского центра изучения общественного мнения (ВЦИОМ), каждая вторая российская семья (51\%) имеет непогашенный кредит. Аналитики агентства «Долговой Консультант» разделили все кредитные долги населения на каждого россиянина и пришли к выводу, что условно каждый житель России трудоспособного возраста имеет задолженность по кредиту в 9848 руб. ${ }^{2}$ Студенты имеют определенные особенности при обращении за потребительским кредитом, т.к. они меньше задумываются о последствиях и не думают о социальной и психологической составляющей такого поведения. Студенты, которые имеют более высокий уровень финансового образования и самообразования, лучше понимают, какие риски могут возникнуть у кредитуемого.

Студенты подвержены различным социальным рискам в обществе, т.к. они амбициозны и жаждут показать себя, а современные тенденции в социальных сетях только усугубляют данную проблему. Блогеры показывают образ успешной жизни, что заставляет студентов стремиться к быстрому обогащению. Чтобы увеличить свой доход, онии идут на неоправданный риск, не думая о последствиях потребительского кредита.

Для изменения ситуации и сокращения числа социальных рисков, которые существуют в обществе, недостаточно провести изменения только в экономической сфере. Основные риски, которые существуют для студента, носят долгосрочный характер: несмотря на высокий рейтинг университета, индивиды получают образование низкого уровня; стремясь получить максимальное число баллов, они чаще прибегают к списыванию вместо практического использования знаний и понимания теории. Если в процессе взросления родители не уделяют достаточно внимания формированию у ребенка рационального подхода к удовлетворению его интересов и потребностей, то не осуществляется полноценная социализация ребенка в современном обществе, что приводит к позднему взрослению и впоследствии влияет на поведение современных студентов. Данные индивиды вырастают в обществе, к которому они не приспособлены, они не используют все его возможности, что ведет к девиантному поведению и росту рискогенности в современном обществе.

Анализируя результаты, которые были получены во время исследования, можно прийти к следующим выводам.

Около $36 \%$ респондентов достаточно обеспечены материально, чтобы денежных средств хватало на покупку автомобиля от 1 млн руб.; у $38 \%$ участников опроса достаточно денег на повседневные расходы, но на покупку автомобиля от 1 млн руб. необходимо взять кредит; у остальных участников денежных средств достаточно, но для покупки одежды нужно немного накопить. Большинство респондентов самостоятельны и полностью отвечают за свои действия, но при этом остаются зависимыми в финансовой и моральной сфере. Каждый респондент имеет близких людей, которые готовы прийти на помощь и оказать действительную помощь при возникших проблемах. В бытовой сфере респонденты часто используют финансовые знания: около $44 \%$ частично используют, около $42 \%$ постоянно используют и только $14 \%$ не используют их совсем. Большинство респондентов не увлекались деятельностью, которая находится в рискогенной сфере, около $54 \%$ не принимали в ней

1 Россияне не собираются влезать в новые долги. Доступ: http://www.ng.ru/ economics/2019-08-07/1_7643_credit.html (проверено 20.03.2021).

2 Долгов мало не бывает. - Российская газета. Федеральный выпуск № 174(7932). Доступ: https://rg.ru/2019/08/07/opros-bolshe-poloviny-rossiian-imeiut-nepogashennye-kredity.html (проверено 20.03.2021). 
участие, около $14 \%$ играли в азартные игры и около $20 \%$ совершали ставки на спорт. В большинстве случаев (около 76\%) респонденты знают определение потребительского кредита, около $36 \%$ могут отличить его от других форм кредита, и только 6\% совсем не слышали о нем. Это говорит о высоком уровне финансового образования и понимании ключевых терминов финансовых организаций в современном мире. $46 \%$ респондентов не нуждаются в потребительском кредите даже при $0 \%$ годовых, что свидетельствует о рациональном использовании студентами своих ресурсов.

Одним из вопросов, который был задан респондентам, был вопрос «Вы доверяете кредитным организациям?» $16 \%$ респондентов испытывают доверие к кредитным организациям, 54\% испытывают доверие отчасти, и только $30 \%$ не доверяют кредитным организациям. Это связано с прошлым негативным опытом использования кредита различных кредитных организаций. Мнения людей разделились, когда был задан вопрос о влиянии кредита на взаимоотношения людей.

Основной причиной взятия потребительского кредита являются проблемы с семьей $(64 \%)$, инвестиции в бизнес $(52 \%)$ и желание купить определенный товар (38\%). Это говорит о том, что потребительский кредит охватывает различные сферы жизни, и в каждом случае он направлен на удовлетворение различных потребностей. Рассмотрим эти направления.

1. Семья продолжает являться главным институтом в обществе. Если в семье возникают проблемы, то они непосредственно отражаются на индивиде в обществе, поэтому студент готов взять кредит для устранения проблемы.

2. Совершать инвестиции в бизнес кредитными средствами достаточно опасно, хотя $90 \%$ малого и среднего бизнеса в России открыто именно на кредитные деньги. В данной сфере происходит удовлетворение потребности либо в занятии любимым делом, либо в увеличении капитала.

3. Покупка определенного товара направлена на краткосрочное удовлетворение потребностей и на улучшение условий повседневной жизни.

Риски присутствуют во всех этих сферах; они постоянно преследуют нас в бизнесе, а наши родные не молодеют, и постоянно возрастает риск проблем со здоровьем. Поэтому респонденты берут потребительский кредит в случаях проблемы с родственниками, при желании инвестировать деньги в бизнес, а также для покупки определенного товара или имущества в кредит.

Несмотря на развитие интернет-технологий, увеличение объема финансовой литературы, университет остается базовым источником финансовых знаний: около $82 \%$ студентов получают теорию именно в данной сфере. При этом свой уровень финансовой грамотности студенты оценивают по-разному: 50\% респондентов - как средний, 24\% - выше среднего, 10\% - высокий, $14 \%$ ниже среднего, и только $2 \%$ - как низкий.

На вопрос: «Как часто Вы читаете финансовую литературу?» - респонденты дали следующие ответы. $42 \%$ читают ее несколько раз в год, $16 \%$ - 1 раз в месяц, $14 \%$ - несколько раз в неделю, остальные совершенно не читают, т.к. финансовая литература им неинтересна. В основном участники нашего исследования отличники и хорошисты, что говорит о должном внимании к учебе со стороны индивидов. У большинства студентов не было опыта в использовании потребительского кредита, $56 \%$ не использовали кредит, $28 \%$ респондентов брали кредит, однако у $68 \%$ участников опросов в семье были практики его использования. В основном никто не влиял на их решение о взятии кредита, а также не возникало каких-либо проблем при его выплате. В конце опроса респондентам предложили выбрать следующие способы получения денег: взять у друга, в семье или в кредитной организации. $10 \%$ респондентов в следующий раз при 
необходимости в денежных средствах возьмут их семье, $12 \%$ - у друга, и $20 \%$ сделают свой выбор в зависимости от ситуации.

Используя результаты данного исследования, мы можем сделать следующие выводы: респонденты прошли все этапы социализации успешно; нет признаков склонности индивидов к девиантному поведению; уровень финансовых знаний у участников опроса достаточно высокий и позволяет сделать правильные выводы о плюсах и минусах потребительского кредитования. Современная молодежь правильно расставляет приоритеты: в первую очередь использовать потребительский кредит для инвестиций в бизнес и для улучшения ситуации в семье. Так, несмотря на увеличение рисков в обществе, студент при правильном воспитании и социализации не склонен к рискогенным ситуациям, характерным для быстро развивающегося мира.

Формирование поведения в современной студенческой среде под влиянием потребительских продуктов происходит умеренно. При этом социальные риски в сфере потребительского кредитования высоки для каждого индивида, особенно в России, где экономические потрясения происходят достаточно часто. Ситуация ухудшается в том случае, когда дело с потребительским кредитом имеет студент с неблагоприятными социальными условиями - здесь возможны попадание в долговую яму, эмоциональное истощение, появление депрессии, что приводит к девиантному поведению и впоследствии - к проблемам в социальных группах. Для улучшения данной ситуации необходимо повышать уровень жизни каждого гражданина нашей страны, а также улучшать финансовое образование каждого индивида. Студенты имеют определенные особенности при обращении к потребительскому кредиту: они меньше задумываются о последствиях и не думают о социальной и психологической составляющей этого действия. Студенты, имеющие более высокий уровень финансового образования, понимают, какие риски могут возникнуть у кредитуемого. Студенты не до конца понимают, какую роль играет потребительское кредитование в их жизни и в жизни государства, поэтому не доверяют кредитным организациям.

В современной России средств для улучшения экономической сферы и развития доверия людей к кредитным организациям недостаточно. Поэтому индивиды должны четко оценивать ситуацию и стремиться к сокращению различных рисков в данной сфере самостоятельно, не ожидая помощи и поддержки со стороны государственных организаций. Сократить социальные риски в сфере потребительского кредитования смогут массовые изменения в сознании людей и общее переосмысление ценностей на протяжении длительного времени, достаточного для изменения данной ситуации. Поэтому уже сейчас необходимо создавать такие условия в обществе, чтобы каждый студент умел грамотно и рационально оценивать ситуацию и принимать правильное решение в отношении кредитных организаций, потребительского кредита и по отношению к миру в целом. Для этого все этапы взросления и социализации ребенка должны проходить вовремя, чтобы влияние на него со стороны социальных групп было минимальным.

Используя различные инструменты в социальной, политической, экономической и социальной сфере, можно изменить и снизить до минимума число возникающих рисков, которые могут привести к негативному опыту использования потребительского кредита, неправильному отношению к потребительским и кредитным организациям. Следует развивать у студентов определенные навыки, чтобы увеличить доверие к кредитным организациям и потребительскому кредиту, при этом сделав момент совершения сделки более рациональным и безопасным. Учебные организации должны создавать специальные 
условия, чтобы взятие потребительского кредитования на получение высшего образования могло быть легко осуществимым. Для человека, который меняет свое социальное положение в обществе, всегда характерны риски. Учитывая амбициозность молодых людей и добавляя к этому их неопытность, мы получаем человека, который находится в рискогенной ситуации. И современное общество должно обратить внимание на данную проблему - применять социологические навыки и накопленный опыт для формирования лучших тенденций в потребительском поведении студентов.

Таким образом, исследование социальных рисков имеет как теоретическое, так и практическое значение. В динамично развивающемся обществе, в условиях реформ и непрерывной модернизации российского общества число социальных рисков и их разнообразие будут только нарастать, особенно в кредитной сфере. Следовательно, актуальность и значимость их исследования будет оставаться на высоком уровне.

RAZOV Pavel Vicktorovich, Dr.Sci. (Soc.), Professor; Deputy Head of the Department of Sociology for Educational and Methodological Work, Financial University under the Government of the Russian Federation (125993, Russia, Moscow, Leningradsky Ave, 49; PVRazov@fa.ru)

BASHKATOV Nikita Evgenyevich, Bachelor of the Faculty of Social Sciences and Mass Communications, Financial University under the Government of the Russian Federation (125993, Russia, Moscow, Leningradsky Ave, 49; bas.nick00 @icloud.com)

\section{THE INFLUENCE OF A CREDIT PRODUCT ON THE CONSUMER BEHAVIOR OF THE RUSSIAN UNIVERSITIES STUDENTS}

\footnotetext{
Abstract. The article is devoted to the study of the subjective and objective factors that create a certain consumer behavior among students of Russian universities under the influence of a loan product. The authors study how various social groups influence on the individuals under conditions of student's socialization, try to identify the level of individual's interaction with social networks and wonder about special conditions for a student in credit institutions and the influence of financial position and social status in society on the formation of consumer behavior.

Keywords: social risk, consumer crediting, student crediting, consumer behavior, credit product, risk society
} 